\title{
The absorption of $\alpha$-tocopherol in man
}

\author{
By J. KELLEHER* AND M. S. LOSOWSKY* \\ Department of Medicine, University of Leeds, \\ The General Infirmary, Leeds $L S_{\text {I }} 3 E X$
}

(Received 23 February 1970-Accepted I7 Fune 1970)

\begin{abstract}
I. Physiological oral doses of $\mathrm{DL}\left[5-\mathrm{Me}-{ }^{3} \mathrm{H}\right] \alpha$-tocopherol were administered to fasting subjects with various disease states, with and without steatorrhoea, and net absorption was calculated by measurement of faecal unabsorbed radioactivity. In each subject studied more than $70 \%$ of the faecal radioactivity was excreted as unchanged $\alpha$-tocopherol.

2. $\alpha$-Tocopherol absorption was significantly less in subjects with steatorrhoea (mean $59.4 \%$, range $3 \mathrm{I}-83 \%$ ) than in those without steatorrhoea (mean $72.4 \%$, range $5 \mathrm{I}-86 \%$ ). Nineteen out of twenty-four subjects with steatorrhoea absorbed less than $65 \%$ of the $\alpha$-tocopherol dose, while twenty-two out of twenty-six subjects without steatorrhoea absorbed more than $65 \%$. There was a significant correlation between the severity of steatorrhoea and $\alpha$-tocopherol absorption. In a wide range of diseases steatorrhoea appeared to be the common factor associated with a decrease in $\alpha$-tocopherol absorption; however, in subjects after gastric surgery $\alpha$-tocopherol absorption was often low even in the absence of steatorthoea, and this may be an important factor in explaining the high incidence of vitamin $\mathrm{E}$ deficiency in such patients.

3. Radioactivity in the plasma was maximal 6-12 h after dosing. Plasma radioactivity curves were significantly lower in patients with steatorthoea than in those without steatorrhoea, but there was considerable overlap. In some patients with severe deficiency and severe steatorrhoea there was no detectable plasma response even with considerable absorption of up to $40 \%$ of the administered dose. Three patients with severe dietary deficiency of the vitamin and no steatorrhoea also showed a decreased plasma radioactivity.

4. Three subjects were studied twice, initially when deficient in $\alpha$-tocopherol and a second time after repletion with $\alpha$-tocopherol acetate. There was no evidence for a compensatory mechanism to increase $\alpha$-tocopherol absorption in $\alpha$-tocopherol deficiency.

5. A small quantity of the administered dose (almost always less than $6 \%$ ) was excreted in the urine.
\end{abstract}

Deficiency of vitamin $\mathrm{E}$ ( $\alpha$-tocopherol) as judged by subnormal plasma levels is known to occur in patients with steatorrhoea (Darby, Ferguson, Furman, Lemley, Ball \& Meneely, 1949; Binder, Herting, Hurst, Finch \& Spiro, 1965; Losowsky \& Leonard, 1967), and since vitamin E is fat-soluble it seems likely that the cause of the deficiency is diminished absorption. In most studies in man absorption has been assessed from plasma levels, which depend in part on factors other than absorption (Klatskin \& Krehl, I950; Week, Sevigne \& Ellis, 1952). In the two reported studies in which measurements of unabsorbed faecal vitamin $\mathrm{E}$ were made (Klatskin \& Molander, 1952; Rosenkrantz, Milhorat \& Farber, 1953), large unphysiological doses were used and the methods of analysis were probably not specific for vitamin $\mathrm{E}$. Blomstrand \& Forsgren (I968a) have recently reported the administration of physiological amounts of ${ }^{14} \mathrm{C}$-labelled $\mathrm{DL}-\alpha$-tocopherol acetate and ${ }^{3} \mathrm{H}$-labelled DL- $\alpha$-tocopherol in two patients and measurement of the resulting radioactivity in lymph, and suggested absorptions of from $21 \cdot 3$ to $28 \cdot 5 \%$.

* Present address: Department of Medicine, St James's Hospital, Leeds, LS 97 TF. 
This paper reports the results of a study of the absorption of physiological amounts of $\alpha$-tocopherol in human subjects with and without steatorrhoea by oral administration of $\mathrm{DL}\left[5-\mathrm{Me}-{ }^{3} \mathrm{H}\right] \alpha$-tocopherol and measurement of resulting radioactivity in faeces, serum and urine.

\section{MATERIALS AND METHODS}

Materials. DL $\left[5-\mathrm{Me}-{ }^{3} \mathrm{H}\right] \alpha$-tocopherol with a specific activity of $\mathrm{I} \mathrm{mCi} / \mathrm{mg}$ was purchased commercially (The Radiochemical Centre, Amersham, Buckinghamshire, England). Its purity was not less than $95 \%$ on receipt, and it was never used if the purity dropped to less than $92 \%$, as determined by thin-layer chromatography. All solvents and chemicals were Analar grade, and were used without further purification.

Plasma $\alpha$-tocopherol. This was measured colorimetrically by the method of Emmerie \& Engel (1939) after saponification, extraction with hexane and thin-layer chromatography as described by Bieri \& Prival (1965). The lower limit of normal is taken as $500 \mu \mathrm{g} / \mathrm{I} 00 \mathrm{ml}$.

Faecal fat. The method was that of van de Kamer, Huinink \& Weyers (1949) as modified by Frazer (1960), on 6 or $7 \mathrm{~d}$ balance periods, with continuous chromium marking (Rose, 1964) to correct for possible irregularity of bowel habit. The upper limit of normal is taken as $6 \mathrm{~g} / \mathrm{d}$ (Dyer \& Dawson, I968).

Procedure for radioactive absorption test. A portion ( $15^{-20} \mu \mathrm{Ci}$ ) of the radioactive DL- $\alpha$-tocopherol, dissolved in $2 \mathrm{ml}$ arachis oil containing $0.2 \mathrm{mg}$ of carrier $\alpha$-tocopherol, was given to fasting subjects and washed down with $100 \mathrm{ml}$ milk (the $\alpha$-tocopherol content of the milk was measured in our laboratory and did not exceed $20 \mu \mathrm{g} / \mathrm{I} 00 \mathrm{ml})$. The subjects were then fasted for a further $4 \mathrm{~h}$. Faeces were collected in $3 \mathrm{~d}$ pools for the next $12 \mathrm{~d}$. It became evident after the first twenty tests that significant activity did not appear after the first $6 \mathrm{~d}$ and only rarely after the first $3 \mathrm{~d}$. Hence in later tests only the first two $3 \mathrm{~d}$ collections of faeces were analysed initially; succeeding specimens were analysed only if more than $5 \%$ of the administered dose was present in the second $3 \mathrm{~d}$ collection. Urine was collected in twenty-seven of the fifty subjects studied for the $6 \mathrm{~d}$ following administration. In twenty-nine of the fifty subjects studied, blood samples were collected into heparinized tubes at 2-hourly intervals from 4 to $8 \mathrm{~h}$ after the oral dose, then at $\mathrm{I} 2$ and $24 \mathrm{~h}$ and then daily to $7 \mathrm{~d}$.

Faecal radioactivity. Faecal specimens were pooled as two $3 \mathrm{~d}$ collections and then one $6 \mathrm{~d}$ collection. On completion, each collection was homogenized at $13000 \mathrm{rev} / \mathrm{min}$ for 3-5 min, and $10 \mathrm{~g}$ portions were analysed in duplicate immediately or stored at $-20^{\circ}$ until analysed. Each portion was mixed thoroughly with anhydrous sodium sulphate powder to dry the specimen and extracted in a Soxhlet apparatus with $200 \mathrm{ml}$ acetone for $2.5 \mathrm{~h}$. Carrier DL- $\alpha$-tocopherol $(5 \mathrm{mg})$ was added to one of each pair of specimens before extraction to estimate the efficiency of recovery, and to act as an antioxidant for the small amount of radioactive material present. The lipid extract was partitioned into $100 \mathrm{ml}$ light petroleum (b.p. $40-60^{\circ}$ ) from an acetone-water mixture $(\mathrm{I}: \mathrm{I}, \mathrm{v} / \mathrm{v})$. The light petroleum was evaporated under reduced pressure and the dry residue was taken up in $8 \mathrm{ml} 5 \%$ pyrogallol in ethanol, placed in a boiling 
water-bath under reflux and, when the solution was boiling, $2 \mathrm{ml} 16 \mathrm{~N}-\mathrm{KOH}$ were added and saponification was continued for $10 \mathrm{~min}$. The non-saponifiable material was extracted into $3 \times 20 \mathrm{ml}$ diethyl ether. The ether was evaporated and the residue was taken up in $5 \mathrm{ml}$ light petroleum. Portions $(0.5 \mathrm{ml})$ were measured into counting vials and evaporated to dryness. The remainder of the extract was purified on a column of Decalso F (Diplock, Edwin, Bunyan \& Green, 196r) and portions of the purified eluate were measured into counting vials and evaporated. The method is basically that of the Society for Analytical Chemistry: Analytical Methods Committee (1959), with modifications as described by Edwin, Diplock, Bunyan \& Green (1960). Portions of the light petroleum extract from the sample with added carrier were also chromatographed on thin-layer plates of silica gel and the distribution of radioactivity between unchanged DL- $\alpha$-tocopherol and oxidation products was determined. The following solvent systems have been used for unidimensional runs: (1) ethyl acetate: hexane (15:85) (Tendille, Bats, Gervais \& Gaborit, 1965); (2) diisopropyl ether: light petroleum: acetone: ethyl ether: glacial acetic acid $(85: 12: 4: \mathrm{I}: \mathrm{I})$ (Stowe, 1963); (3) cyclohexane:chloroform (2:1) (Skinner, Parkhurst \& Alaupovic, I964).

Plasma radioactivity. Portions $(2 \mathrm{ml})$ of plasma were extracted with hexane after saponification. The hexane was transferred to counting vials and evaporated to dryness. On four occasions parallel extractions were carried out with chloroform: methanol $(2: I, v / v)$ (Folch, Lees \& Stanley, 1957) and, since this gave results identical to those with the simpler hexane extraction, the latter was used routinely. To determine the distribution of radioactivity between $\alpha$-tocopherol and its metabolites in plasma, portions of hexane extracts were evaporated to dryness, taken up in successive portions (approximately $0.05 \mathrm{ml}$ ) of benzene and transferred quantitatively to silica gel thin-layer plates and chromatographed, using the solvents listed previously. Areas corresponding to unchanged $\alpha$-tocopherol and to $\alpha$-tocopherolquinone were scraped off, eluted with ethanol, transferred quantitatively to counting vials and evaporated to dryness. The remainder of the chromatogram was divided into $2 \mathrm{~cm}$ strips, eluted and counted similarly. Plasma counts were expressed as counts/min per ml plasma per $\mathrm{kg}$ body-weight per $0.15 \mu \mathrm{Ci}$ administered. These corrections are included to allow for variations in body-weight and any small differences in the total doses administered to individual patients.

Counting procedure for plasma and faecal extracts. To each dried extract were added $8 \mathrm{ml}$ toluene containing $0.4 \%$ 2,5-diphenyloxazole (PPO) and $0.01 \%$ I,4-di-[2(5-phenyloxazolyl)]benzene (POPOP). Radioactivity was measured in a Packard Tri-Carb automatic liquid scintillation counter model 527 , the minimum counts being four to five times the background of I2-I4 counts/min. The efficiency was $33 \%$. Quenching was corrected for by the external standardization channel ratio method.

Urine radioactivity. A portion $(0.5 \mathrm{ml})$ of each urine specimen was diluted with ro ml of Bray's scintillation solution (Bray, 1960) and counted as above.

Calculation of net absorption. It was assumed that any radioactive $\alpha$-tocopherol not excreted in the faeces had been absorbed. Net absorption was calculated by 
subtracting the faecal radioactivity from the total radioactivity administered and expressing this difference as a percentage of the total dose administered.

Statistical methods. Means of groups were compared by Student's $t$ test and correlation coefficients calculated with the Bravais-Pearson coefficient of linear correlation.

Table I. Subjects studied

\begin{tabular}{lcc}
\multicolumn{1}{c}{ Diagnosis } & $\begin{array}{c}\text { No. of } \\
\text { patients }\end{array}$ & $\begin{array}{c}\text { No. with } \\
\text { steatorrhoea }\end{array}$ \\
Cirrhosis & I6 & 7 \\
Primary biliary cirrhosis & 2 & 2 \\
Post-gastrectomy & 8 & 4 \\
Gluten-sensitive enteropathy & 5 & 3 \\
Crohn's disease & 4 & 4 \\
Chronic pancreatic dysfunction & 3 & 2 \\
Small-bowel resection & I & I \\
Jejunal diverticula & I & I \\
Mild iron or folic acid deficiency & 3 & 0 \\
Obesity & I & $\circ$ \\
Thyrotoxicosis & I & 0 \\
Hyperparathyroidism & I & 0 \\
Diabetes mellitus & I & 0 \\
Paget's disease of bone & I & $\circ$ \\
Dietary osteomalacia & I & 0 \\
Duodenal ulcer & I & 0 \\
$\quad$ Total & 5o & 24
\end{tabular}

Subjects studied. Fifty subjects were studied, all of whom were undergoing investigation for malabsorption in a metabolic unit. The diagnoses are shown in Table $\mathbf{I}$. The patients with cirrhosis all had the diagnosis proved by liver biopsy. Of the five patients with gluten-sensitive enteropathy, two had previously been shown to have steatorrhoea and had been successfully treated with a gluten-free diet for 2 and 3 years and did not have steatorrhoea when studied. The other three patients with steatorrhoea had a subsequent satisfactory response to a gluten-free diet. The three patients with chronic pancreatic disease had the diagnosis proved at autopsy or at laparotomy. The diagnosis for the four patients with Crohn's disease was proved by histological examination. The subject with osteomalacia had been taking a very poor diet; no disease was discovered despite extensive investigation. The remaining patients with diagnoses other than those given above, and who were all shown not to have steatorrhoea, have been grouped together as control patients. Three of these subjects, who were vitamin E-deficient when first studied, were repleted with $200 \mathrm{mg}$ $\alpha$-tocopherol acetate orally per day for 3 months and then had the absorption test repeated. The oral supplements were omitted on the day the absorption test was performed.

\section{RESULTS}

\section{Plasma $\alpha$-tocopherol levels}

Plasma $\alpha$-tocopherol levels were significantly lower $(P<0.025)$ in the patients with steatorrhoea, mean $477 \mu \mathrm{g} / \mathrm{I} 00 \mathrm{ml}$, than in those without steatorrhoea, mean $650 \mu \mathrm{g} / 100 \mathrm{ml}$ (Fig. I). 


\section{Net absorption of $\alpha$-tocopherol}

The net absorption of $\alpha$-tocopherol in patients with and without steatorrhoea is shown in Fig. 2. The mean absorption for those with steatorrhoea was $59.4 \%$, range $3 \mathrm{I}-83 \%$, and for those without steatorrhoea $72 \cdot 4 \%$, range $5 \mathrm{I}-86 \%$. While a considerable overlap existed, the means for the two groups were significantly different $(P<0.001)$.

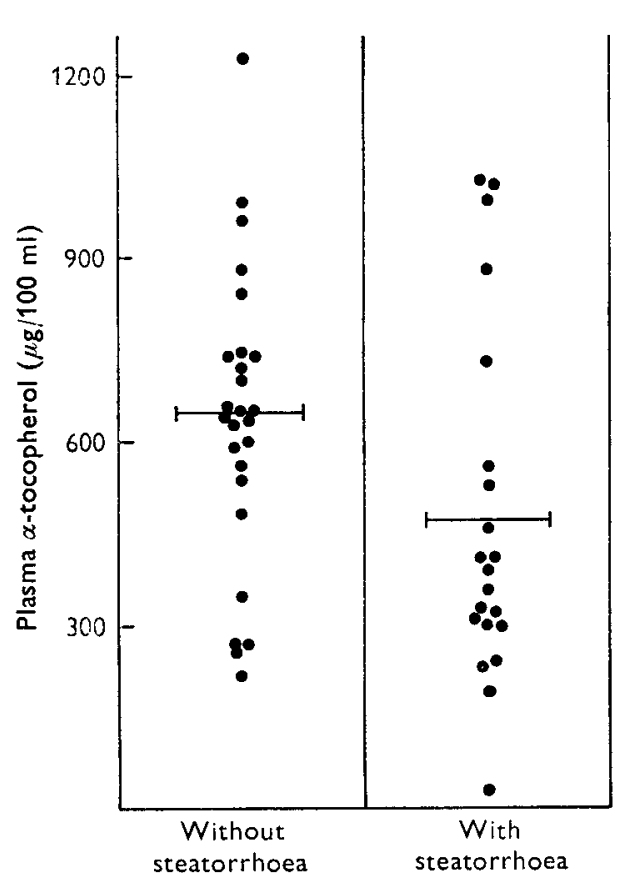

Fig. I

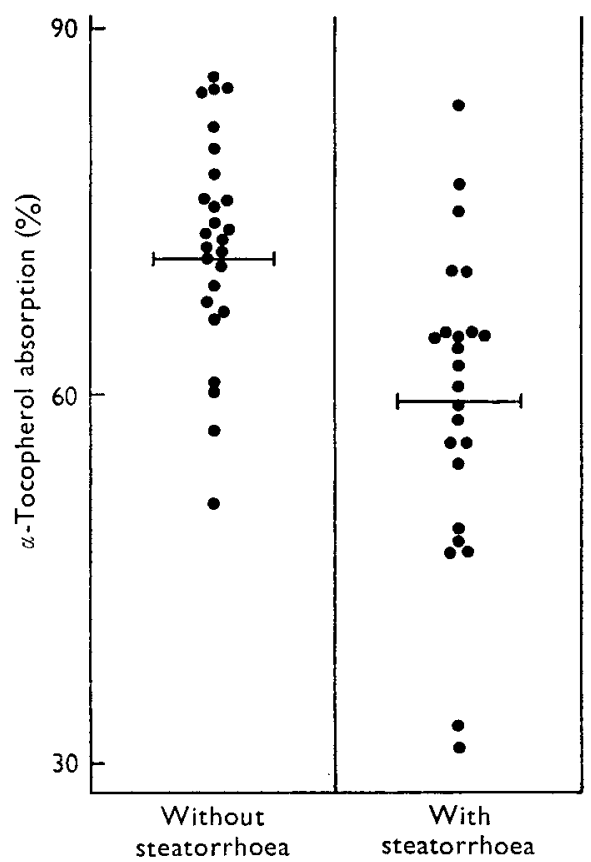

Fig. 2

Fig. I. Plasma $\alpha$-tocopherol levels in human subjects with and without steatorrhoea. The values for three subjects who had been given supplements of $\alpha$-tocopherol were excluded.

Fig. 2. $\alpha$-Tocopherol absorption in human subjects with and without steatorrhoea.

The net absorption of $\alpha$-tocopherol in the various disease states studied is shown in Fig. 3. There was no significant difference in the absorption between the control group and the patients with cirrhosis of the liver without steatorrhoea $(P<0 \cdot \mathbf{I})$, but in patients with cirrhosis (excluding primary biliary cirrhosis) and steatorrhoea the absorption was significantly less than in either of the above two groups $(P<0.00 \mathrm{I}$ and $P<0.005$ respectively). The two patients with primary biliary cirrhosis had steatorrhoea ( 12.9 and $7 \cdot \mathrm{I} \mathrm{g}$ faecal fat/d) and $\alpha$-tocopherol absorptions of 49 and $64 \%$ respectively. The two patients with treated coeliac disease had absorptions well up in the non-steatorrhoea range, and the values for the three untreated patients, all of whom had steatorrhoea, were much lower. Two of the three patients with chronic pancreatic disease had severe steatorrhoea ( 37 and $3^{8} \mathrm{~g}$ faecal fat $/ \mathrm{d}$ ) and both had low 
$\alpha$-tocopherol absorptions ( 47 and $56 \%$ ). The third patient, although without steatorrhoea, had an absorption that was nevertheless lower than any of those in the control group. The four patients with Crohn's disease all had steatorrhoea, and in three the absorptions were much less than the lowest value in the group without steatorrhoea. The fourth patient had a faecal fat excretion of $\mathrm{I}_{\mathrm{r}} \cdot 9 \mathrm{~g} / \mathrm{d}$ but absorbed over $80 \%$ of the vitamin. The absorption of $\alpha$-tocopherol in patients after gastrectomy tended to be lower than in the other groups without steatorrhoea. No patient after gastrectomy had

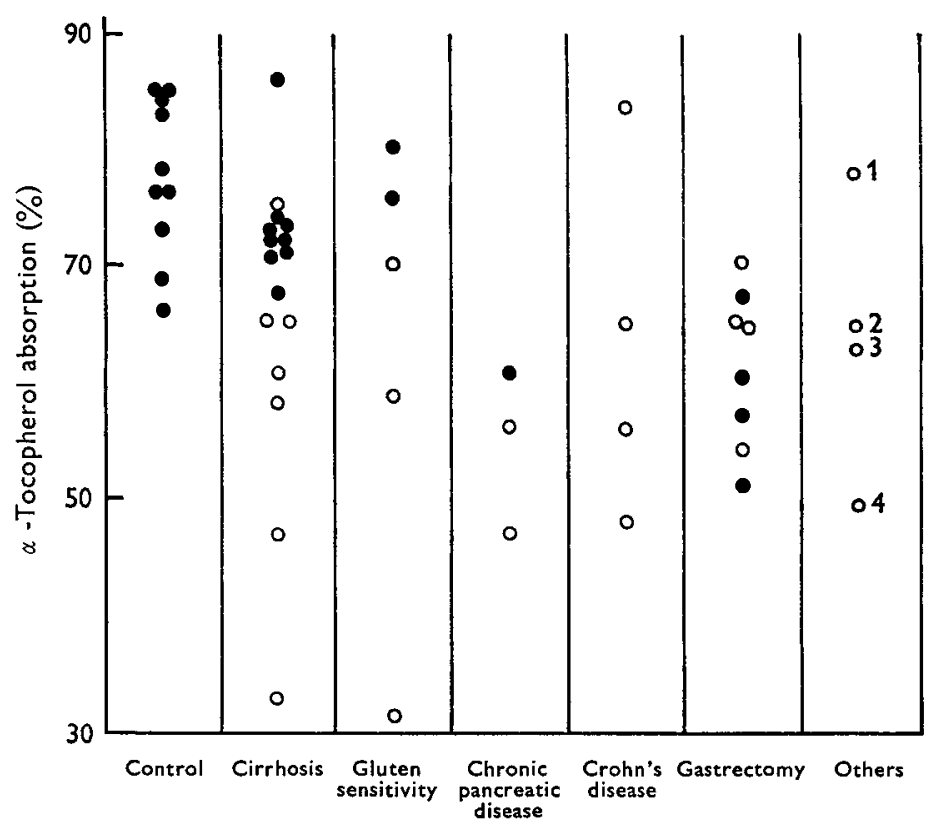

Fig. 3. $\alpha$-Tocopherol absorption in human subjects with $(O)$ and without $(\bullet)$ steatorrhoea separated according to diagnosis. The diagnoses in the last column were small-bowel resection (1), primary biliary cirrhosis $(2,4)$, and jejunal diverticula (3).

severe steatorrhoea, the highest faecal fat levels being $6 \cdot 1,7 \cdot 3,7 \cdot 9$ and $10 \cdot 0 \mathrm{~g} / \mathrm{d}$ and, although the $\alpha$-tocopherol absorption was less than $70 \%$ in all of these, the other four post-gastrectomy patients without steatorrhoea had $\alpha$-tocopherol absorptions just as low. In one patient with small-bowel resection and a faecal fat excretion of $10.8 \mathrm{~g} / \mathrm{d}$, the $\alpha$-tocopherol absorption was $77 \%$, while in the patient with multiple jejunal diverticula, who had mild steatorrhoea $(7 \circ \mathrm{g}$ faecal fat $/ \mathrm{d}), 62 \cdot 4 \%$ of the vitamin was absorbed.

The results for three patients in whom the absorption test was repeated after repletion with $\alpha$-tocopherol acetate are shown in Table 2. It is seen that in all three patients the absorption was similar in the deficient and repleted states.

The relation between the percentage absorption of $\alpha$-tocopherol and the daily faecal fat output in all patients studied is plotted in Fig. 4 and, although the scatter was wide, there was a significant correlation $(r=0.527, P<0.001)$. Only four of 
twenty-six subjects with a faecal fat excretion of less than $6 \mathrm{~g} / \mathrm{d}$ had an $\alpha$-tocopherol absorption of less than $65 \%$, while nineteen of twenty-four subjects whose faecal fat excretion was greater than $6 \mathrm{~g} / \mathrm{d}$ absorbed less than $65 \%$.

Table 2. Absorption of $\alpha$-tocopherol by human subjects before and after repletion with $\alpha$-tocopherol

\begin{tabular}{|c|c|c|c|c|}
\hline \multirow[b]{2}{*}{ Condition of subject } & \multicolumn{2}{|c|}{ Deficient subjects } & \multicolumn{2}{|c|}{ Repleted subjects } \\
\hline & $\begin{array}{c}\text { Serum } \\
\alpha \text {-tocopherol } \\
(\mu \mathrm{g} / \mathrm{1} 00 \mathrm{ml})\end{array}$ & $\begin{array}{c}\alpha \text {-Tocopherol } \\
\text { absorption } \\
(\%)\end{array}$ & $\begin{array}{c}\text { Serum } \\
\alpha \text {-tocopherol } \\
(\mu \mathrm{g} / 100 \mathrm{ml})\end{array}$ & $\begin{array}{c}\alpha \text {-Tocopherol } \\
\text { absorption } \\
(\%)\end{array}$ \\
\hline Cirrhosis (with steatorrhoea) & 330 & $6 \mathrm{r} \cdot 0$ & 1340 & $58 \cdot 0$ \\
\hline Gluten-sensitive steatorrhoea & 234 & $64 \cdot 4$ & 1450 & $59 \cdot 2$ \\
\hline $\begin{array}{l}\text { Mild folic acid deficiency } \\
\text { (no steatorrhoea) }\end{array}$ & 356 & $79 \cdot 8$ & 1480 & $78 \cdot 0$ \\
\hline
\end{tabular}

Faecal radioactivity

In thirty-five of the fifty subjects, less than $6 \%$, and in forty of the fifty subjects less than $10 \%$, of the administered dose appeared after the 3 rd day. The remaining ten subjects included six with steatorrhoea (one with cirrhosis, two Crohn's disease, one gluten sensitivity, one chronic pancreatic disease and one post-gastrectomy), and four without steatorrhoea (one with thyrotoxicosis, one diabetes, one chronic pancreatic disease and one cirrhosis). The late excretion of administered radioactivity in these subjects was as high as $30 \%$ of the dose in four of them, $21 \%$ in one, and in the other five between 10 and $20 \%$. In only two subjects did more than $2 \%$ of the administered radioactivity appear later than the 6th day; one had chronic pancreatic disease without steatorrhoea and excreted $6 \%$ after the 6th day and the other had gluten-sensitive enteropathy with steatorrhoea and excreted $10 \%$ after the 6 th day.

Thin-layer chromatography of the faecal extracts showed that not less than $70 \%$ of the unabsorbed radioactivity was unchanged $\alpha$-tocopherol in any patient. About I0-15\% of the excreted radioactivity was in a single distinct spot with a $R_{F}$ value in several solvent systems (Tendille et al. 1965 ; Stowe, 1963; Skinner et al. 1964) similar to $\alpha$-tocopherolquinone, with which it was identified. The remainder was spread evenly along the rest of the thin-layer plate.

\section{Plasma radioactivity}

The peak of plasma radioactivity occurred between 6 and $12 \mathrm{~h}$ after the oral dose of labelled $\alpha$-tocopherol in every subject in whom plasma curves were examined. A second peak was never found and the shapes of all the plasma curves were similar.

Thin-layer chromatography of plasma extracts from twenty-nine subjects showed that more than $80 \%$ (range $80-96$ ) of the radioactivity in plasma was present as unchanged $\alpha$-tocopherol. The remaining radioactivity was mainly $\alpha$-tocopherolquinone and a smaller (up to $10 \%$ ) unidentified peak of radioactivity was present at the solvent front.

The mean plasma curves from sixteen subjects without steatorrhoea and thirteen subjects with steatorrhoea are shown in Fig. 5. While there was a considerable overlap, 
there was a significant difference between the two groups at each point on the curve except at $4 \mathrm{~h}$.

The relation between the plasma radioactivity at $8 \mathrm{~h}$ and the absorption of the vitamin

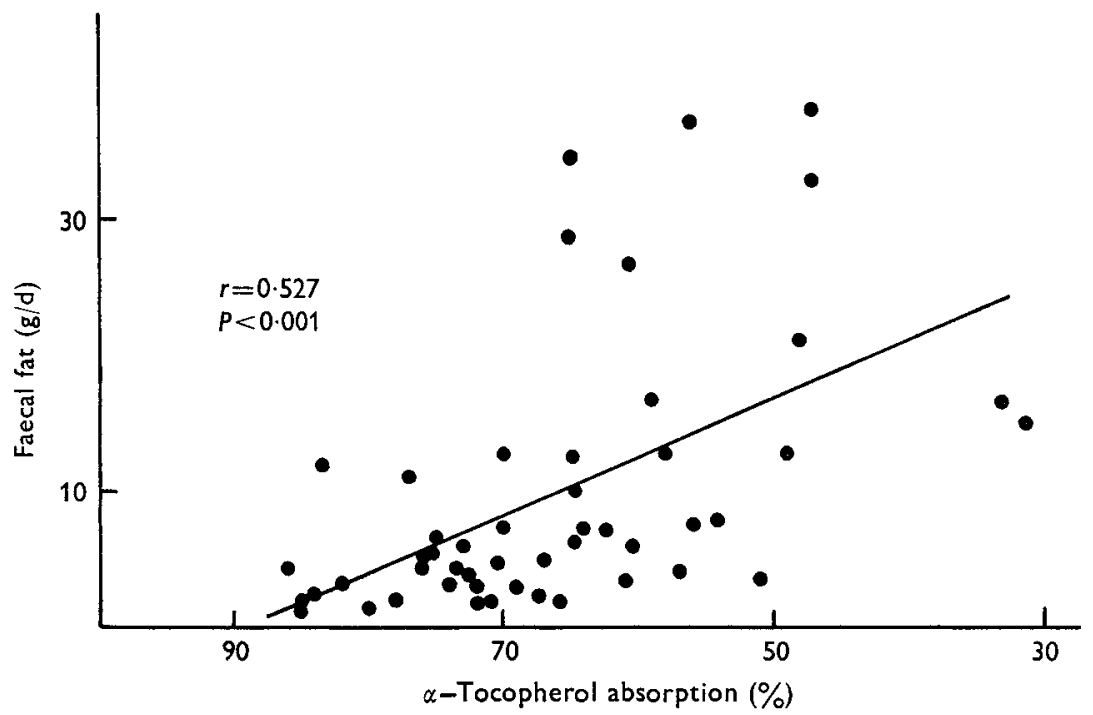

Fig. 4. Relationship between faecal fat excretion and $\alpha$-tocopherol absorption in human subjects with and without steatorrhoea. The diagonal line is the calculated regression line $(y=37 \cdot 3-0.42 x)$.

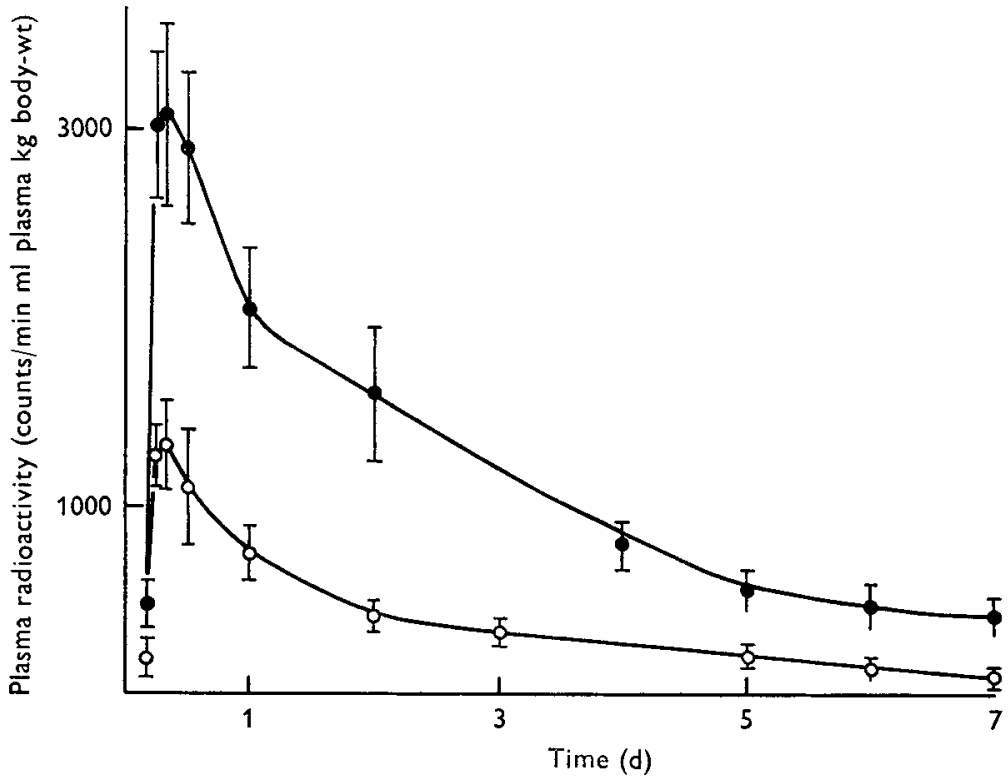

Fig. 5. Mean plasma radioactivity curves for sixteen patients without steatorrhoea $(-)$ and thirteen patients with steatorrhoea $(O-O)$. The vertical bars are the standard errors of the means. The difference was significant at all times $(P<0.05)$ except at $4 \mathrm{~h}(P<0 . \mathrm{I})$. Plasma radioactivity values are corrected for total dose administered. 
is shown in Fig. $6(r=0.627, P<0.001)$. Three patients with low absorptions, between $3 \mathrm{I}$ and $48 \%$, failed to show any plasma radioactivity, and all three were extremely severely depleted of the vitamin as judged by plasma levels, and all had gross steatorrhoea. Similarly, three patients with severe dietary $\alpha$-tocopherol deficiency but without steatorrhoea seemed to form a distinct group lying above the others on the graph, the plasma peak never reaching expected levels.

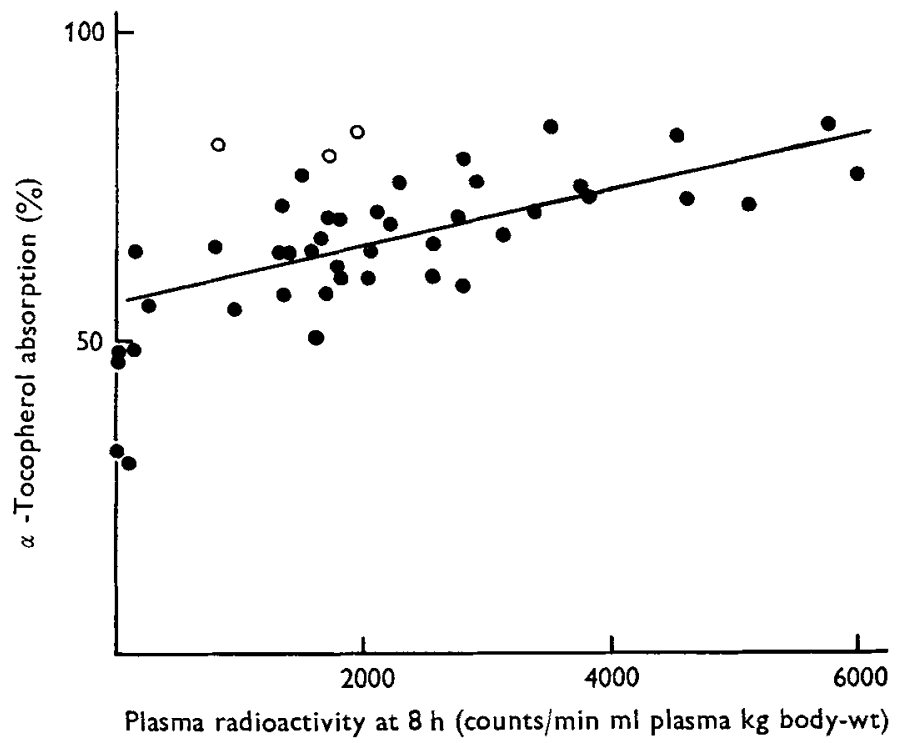

Fig. 6. Relationship in human subjects between plasma radioactivity at $8 \mathrm{~h}$ after dosing with $\alpha$-tocopherol and $\alpha$-tocopherol absorption. $\bigcirc$, patients with dietary deficiency of $\alpha$-tocopherol; - patients with an adequate dietary intake of $\alpha$-tocopherol. Plasma radioactivity values are corrected for total dose administered. The diagonal line is the calculated regression line $(y=57.2-0.0045 x) ; r=0.627 ; P<0.001$.

\section{Urine activity}

In twenty-five out of twenty-seven subjects the total urine excretion did not exceed $6 \%$ of the administered dose and, in seventeen out of twenty-seven, it was less than $4 \%$. Two subjects, one with Crohn's disease and steatorrhoea and the other a gastrectomy patient without steatorrhoea, excreted $7 \cdot 2$ and $7 \cdot 5 \%$ of the oral dose respectively. Of the excreted radioactivity, more than $75 \%$ was in the urine excreted during the $48 \mathrm{~h}$ following the oral dose and, by the 6 th day, less than $0.1 \% / \mathrm{d}$ was being excreted. The nature of this urine radioactivity was not studied further.

\section{DISCUSSION}

\section{Completeness of absorption}

That the absorption of $\alpha$-tocopherol is incomplete is suggested by many studies in animals (Krishnamurthy \& Bieri, 1963; Simon, Gross \& Milhorat, 1956) and a small number of studies in man (Klatskin \& Molander, 1952; Rosenkrantz et al. 1953). 
This appears to be true for all the fat-soluble vitamins. Thompson, Lewis \& Booth (1966) found $78 \%$ absorption of cholecalciferol, Blomstrand \& Werner (1967) 6-60\% absorption of retinol, and Blomstrand \& Forsgren (1968b) $60 \%$ of phylloquinone. Blomstrand \& Forsgren (1968a) studied the absorption of vitamin $\mathrm{E}$ in two patients with cannulated thoracic ducts. In one subject with a gastric carcinoma absorption of DL- $\alpha$-tocopherol acetate was $2 \mathrm{I} \cdot 3 \%$ and in the other patient with chronic lymphatic leukaemia the absorption of DL- $\alpha$-tocopherol acetate was $25 \%$ and the absorption of DL- $\alpha$-tocopherol was $28.5 \%$. There are several possible reasons for these absorption results being lower than the values reported in this study. It has not been established that $\alpha$-tocopherol absorption is exclusively by the lymphatic route; lymph collection via the thoracic duct in man may not be complete owing to anatomic variations (Kayden, Senior \& Mattson, 1967), and the same authors stated that recoveries of labelled fatty acids in lymph triglycerides in man are low, ranging from only $25-60 \%$, and malabsorption does not appear to have been excluded in these ill patients. Furthermore, the present study has estimated net absorption from all levels of the gastrointestinal tract, and it seems possible that absorption of the vitamin could continue for longer than the $24 \mathrm{~h}$ studied by Blomstrand \& Forsgren (I968a).

There is evidence that $\alpha$-tocopherol is excreted in the bile (Klatskin \& Molander, 1952; Schmandke \& Proll, 1964) and this could be re-absorbed and constitute an entero-hepatic circulation. However, Mellors \& Barnes (1966) failed to detect radioactivity in bile from rats given oral doses of ${ }^{14} \mathrm{C}$-labelled $\alpha$-tocopherol, Schmandke $\&$ Proll ( 1964 ) found only $0.8 \%$ of an intravenously administered dose appearing in the bile and Klatskin \& Molander (1952) found no increase in bile levels following oral administration of $\alpha$-tocopherol in man. Thus, the biliary excretion and entero-hepatic circulation of newly absorbed $\alpha$-tocopherol seem unlikely to have a significant effect on the net absorption as we have determined it.

\section{Mechanism of absorption}

Little is known about the mechanism of absorption of $\alpha$-tocopherol. However, it does appear that the free alcohol is absorbed as such, while the ester is hydrolysed during or soon after absorption, for several studies have shown that increases in plasma levels obtained after oral doses of the acetate ester are due to the presence of the free alcohol (Filer, Wright, Manning \& Mason, 1951; Pelkonen, 1963). Furthermore, Blomstrand \& Forsgren (1968a) showed in a patient who received an oral dose of ${ }^{14} \mathrm{C}$-labelled DL- $\alpha$-tocopherol acetate that over $90 \%$ of the radioactivity in the thoracic duct lymph was present as the free alcohol. Wiss, Bunnell \& Gloor (1964), however, suggested that $\alpha$-tocopherol acetate might be partly absorbed as the unchanged ester and partly as the free alcohol resulting from hydrolysis of the ester in the intestine, although, in contrast, orally administered vitamin $\mathrm{A}$, whether free or esterified, appears in the intestinal mucosal cells (Ganguly, Krishnamurthy \& Mahadevan, 1959) and thoracic duct lymph (Goodman, Blomstrand, Werner, Huang \& Shiratori, r966; Blomstrand \& Werner, 1967) almost entirely as the palmitate.

That $\alpha$-tocopherol absorption is linked with fat absorption is clear from various reports. Darby et al. (1949) and Losowsky \& Leonard (1967) found low plasma levels 
of the vitamin in patients with steatorrhoea, and Hashim \& Schuttringer (I966) and Filer et al. (195I) found no increase in plasma levels after oral administration of the vitamin to subjects with severe steatorrhoea. These results, taken with the findings now reported, support the view that $\alpha$-tocopherol absorption is reduced in patients with steatorrhoea. It has been suggested (Pomeranze \& Lucarello, 1953) that $\alpha$-tocopherol absorption follows fat absorption closely, that the route of absorption is probably lymphatic (Blomstrand \& Forsgren, 1968 $a$; Johnson \& Pover, 1962), and that most of the absorbed vitamin is located in the chylomicrons. McCormick, Cornwell \& Brown (1960) showed that the increment in serum tocopherol from newly absorbed $\alpha$-tocopherol is found first in the chylomicrons and Sf 10-40o lipoproteins. The transport of newly absorbed $\alpha$-tocopherol in chylomicrons in the lymphatics would be similar to that for vitamin A (Goodman et al. 1966; Blomstrand \& Werner, I967) and cholecalciferol (Avioli, 1969) and also for the absorption of dietary triglycerides (Senior, 1964; Kayden et al. 1967). In the rare syndrome of abetalipoproteinaemia, in which there is a defect of chylomicron formation and an absence of fat absorption into lymphatics (Ways, Parmentier, Kayden, Jones, Saunders \& Rubin, I967), there also appears to be an absence of $\alpha$-tocopherol absorption, as judged by the response of plasma $\alpha$-tocopherol levels to prolonged oral administration of $\alpha$-tocopherol acetate (Kayden \& Silber, 1965). The fact, however, that some fat absorption does occur in these patients, possibly via the portal vein (Ways et al. 1967), might suggest that unless it is entirely taken up by the liver in the first circulation $\alpha$-tocopherol cannot be absorbed into the portal vein. However, Dodge, Cohen, Kayden \& Phillips (1967) and Muller \& Harries (1969), using large doses of water-miscible $\alpha$-tocopherol in patients with abetalipoproteinaemia, did produce some response in plasma levels. Perhaps, therefore, if lymphatic absorption is blocked, absorption of water-miscible preparations by the portal route assumes importance. Furthermore, Schmandke (1967) demonstrated higher post-absorptive $\alpha$-tocopherol levels in portal as compared with peripheral blood in rats, suggesting some degree of absorption via the portal vein.

The lack of a closer correlation between $\alpha$-tocopherol absorption and faecal fat in our patients may have been caused in part by the diversity of their disease states, which may have had different effects on $\alpha$-tocopherol absorption and faecal fat. Furthermore, the method we have used for performing the absorption test may explain the overlap between patients with and without steatorrhoea in that we have used tracer doses of the vitamin, which may not require maximal absorptive activity. The presence of bile is thought to be necessary for normal absorption of vitamin E (Klatskin \& Tisdale, 1957; Greaves \& Schmidt, 1937; Brinkhous \& Warner, 194I) and this may be related to the role of bile salts in the formation of lipid micelles for fat absorption (Hofmann \& Borgström, 1962, 1964). Studies in animals suggest that no one part of the gastro-intestinal tract is responsible for $\alpha$-tocopherol absorption (Sternberg \& Pascoe-Dawson, 1959; Desai, Parekh \& Scott, 1965) and sufficient information is not yet available for human subjects to decide if any specific site exists. 


\section{Plasma curves}

The plasma content of newly absorbed vitamin $E$ at any time will depend on several factors, the most important of which are probably the rate of absorption, the rate of transfer to the tissues and the quantity of transporting lipoprotein present in the plasma (Davies, Kelleher \& Losowsky, r969).

The time of peak plasma activity, 6-12 $\mathrm{h}$ after administration, found in our studies is very similar to that found by other authors, who used large doses of unlabelled vitamin E (Filer et al. 195 I Week et al. 1952), labelled cholecalciferol (Thompson et al. 1966) and unlabelled vitamin A (Harris, 1960). Since the height of the plasma peak depends on other factors as well as absorption, it is perhaps to be expected that there would not be a close correlation between total absorption and the height of the plasma peak, and a similar lack of close correlation has been observed after oral doses of physiological amounts of cholecalciferol (Thompson et al. 1966). This is illustrated by the three of our patients without steatorrhoea, who had a vitamin E deficiency of dietary origin and whose plasma peaks were lower than in other patients with similar net absorptions. It seems likely that in these three patients there was a rapid transfer of newly absorbed vitamin to the tissues, reducing the accumulation in the plasma; also in animal experiments (Kelleher, Davies \& Losowsky, 1969) the uptake of $\alpha$-tocopherol by the tissues has been shown to be very much greater in deficient than in supplemented or normal animals. Similarly, in some of the subjects with severe steatorrhoea and severe deficiency, as shown by very low plasma $\alpha$-tocopherol levels, there was no detectable plasma radioactivity even though as much as $3 \mathbf{I}-47 \%$ of the dose was absorbed. The absence of an increase in plasma $\alpha$-tocopherol concentration in patients with severe steatorrhoea has also been shown by other workers using large oral doses of the vitamin (Filer et al. 195 ; Hashim \& Schuttringer, 1966). While absorption is diminished in such patients, it is still considerable, and the rapid uptake of the absorbed vitamin by severely depleted tissues may be even more important.

In patients with steatorrhoea the concentration of low-density lipoproteins is often reduced (Lloyd, 1969) and, as these are the major transporting proteins for $\alpha$-tocopherol (McCormick et al. 1960; Davies et al. 1969), it may well be that this reduction would contribute to lowered plasma levels.

\section{Absorption in disease states}

Based on their measurements of faecal excretion, Klatskin \& Molander (1952) made the suggestion that the absorption of $\alpha$-tocopherol is greater in patients with cirrhosis than in control convalescent subjects, but in a later paper (Klatskin, 1954) one of the same authors suggests that the relatively low faecal excretion may be due to increased intestinal destruction of $\alpha$-tocopherol in patients with cirrhosis. Increased absorption in such patients was not found in our study and, in the absence of steatorrhoea, there was no significant difference between the absorption of $\alpha$-tocopherol by subjects with cirrhosis and by the control group of subjects. In patients with cirrhosis and steatorrhoea, the absorption of $\alpha$-tocopherol was diminished, as it was in those with steatorrhoea accompanying other diseases. 
In patients after gastrectomy, steatorrhoea was never severe and was present in only four of the eight subjects, yet only two of the eight subjects had vitamin $\mathrm{E}$ absorptions within the control range. This suggests that impaired absorption of $\alpha$-tocopherol may be common in such patients, even in the absence of steatorrhoea, which is also suggested by the findings of Gounelle, Marnay \& Blondin (1953), who showed that the plasma $\alpha$-tocopherol tolerance curve is significantly lower after gastrectomy than in normal subjects. The poor absorption could be partly due to an altered dietary habit, since Pomeranze \& Lucarello (1953) produced evidence that $\alpha$-tocopherol absorption is diminished in patients on a low fat intake, but there are, of course, other disturbances of gastro-intestinal physiology after gastrectomy (Lundh, 1962 ), that may well affect the absorption of vitamin E. Losowsky, Leonard, Kelleher \& Pulvertaft (1967), in a series of over 1000 patients after gastric surgery, showed that $26 \%$ had evidence of deficiency of vitamin $\mathrm{E}$. While diminished absorption may be a factor in causing deficiency, dietary intake may also be low in these subjects (Barker, Malm \& Roemtsma, I960).

\section{Absorption in depleted subjects}

In the three patients whom we have studied both in a depleted state and then $2-3$ months later after repletion with $\alpha$-tocopherol, the absorption was similar on both occasions. This seems to apply whether or not there is steatorrhoea, since two of the subjects had steatorrhoea (which did not alter during the period) whereas the third did not have steatorrhoea. The results at first sight appear at variance with those of Schmandke ( 1967 ), who has suggested that absorption of vitamin $E$ is less efficient in deficient than in normal rats, and of Desai et al. (1965) who found similar results in chicks. However, Schmandke used the liver level of radioactivity to assess absorption, and this method, in our experience (Kelleher et al. 1969), may not be valid in deficient animals. Desai et al. (1965) measured the uptake of radioactivity in ligated intestinal loops over short time intervals $(5 \mathrm{~min})$, and it is unlikely that such studies would indicate the net absorption. It appears, however, from our results that in man when there is a deficiency of $\alpha$-tocopherol there is no compensatory mechanism to increase the efficiency of its absorption, as there is for iron absorption in iron deficiency (Bothwell, 1968).

\section{Excretion in the urine}

The small percentage of the oral dose excreted in the urine by the subjects in this study, $67 \%$ of whom excreted less than $4 \%$ of the administered dose in the urine, is in agreement with the results of other workers with animals (Simon et al. 1956; Johnson \& Pover, 1962). This suggests that urine is not an important excretory pathway for absorbed $\alpha$-tocopherol. These results contrast with those of Sternberg \& Pascoe-Dawson (1959), who found a cumulative urine excretion of $37 \%$ in rats given an oral tracer dose of $\alpha$-tocopherol.

We are grateful to Mrs Anne A. Spencer and Miss Barbara M. McDermott-Rowe for expert technical assistance, to Sister Walker and her staff in our Metabolic Unit for their excellent co-operation in the handling of patients and collection of specimens, to Dr J. Green of Beecham Research Laboratories for gifts of pure DL- $\alpha$-tocopherol, 
to Dr J. Pennock of Liverpool University for a gift of $\alpha$-tocopherolquinone and to Roche Products Limited and the Medical Research Council for financial assistance.

\section{REFERENCES}

Avioli, L. V. (1969). Am. F. clin. Nutr. 22, 437.

Barker, H. G., Malm, J. H. \& Roemtsma, K. (1960). N.Y. St. F. Med. 60, 1783.

Bieri, J. G. \& Prival, E. L. (1965). Proc. Soc. exp. Biol. Med. 120, 554.

Binder, H. J., Herting, D. L., Hurst, V., Finch, S. C. \& Spiro, H. M. (1965). New Engl. F. Med. 273, 1289.

Blomstrand, R. \& Forsgren, L. (I968a). Int. Z. VitaminForsch. 38, 328.

Blomstrand, R. \& Forsgren, L. (1968b). Int. Z. VitaminForsch. 38, 45.

Blomstrand, R. \& Werner, B. (1967). Scand. J. clin. Lab. Invest. r9, 339.

Bothwell, T. H. (1968). Br. F. Haemat. 14, 453 .

Bray, G. A. (1960). Analyt. Biochem. I, 279.

Brinkhous, K. M. \& Warner, E. D. (1941). Am. F. Path. 17, 8I.

Darby, W. J., Ferguson, M. E., Furman, R. H., Lemley, J. M., Ball, C. T. \& Meneely, G. R. (1949). Ann. N.Y. Acad. Sci. 52, 328.

Davies, T., Kelleher, J. \& Losowsky, M. S. (I969). Clinica chim. Acta 24, 43 I.

Desai, I. D., Parekh, C. K., \& Scott, M. I. (1965). Biochim. biophys. Acta 100, 280.

Diplock, A. T., Edwin, E. E., Bunyan, J. \& Green, J. (196r). Br. F. Nutr. r5, 425.

Dodge, J. T., Cohen, G., Kayden, H. J. \& Phillips, G. B. (1967). F. clin. Invest. 46, 357.

Dyer, N. H. \& Dawson, A. M. (1968). Br. med. F. ii, 225.

Edwin, E. E., Diplock, A. T., Bunyan, J. \& Green, J. (1960). Biochem. J. 75, 450.

Emmerie, A. \& Engel, C. (1939). Recl. Trav. chim. Pays-Bas Belg. 57, 1351.

Filer, L. J., Wright, S. W., Manning, M. P. \& Mason, K. E. (195I). Paediatrics, Cairo 8, 328.

Folch, J., Lees, M. \& Stanley, G. H. S. (1957). F. biol. Chem. 226, 497.

Frazer, A. C. (1960). Association of Clinical Pathologists: Broadsheet no. 28.

Ganguly, J., Krishnamurthy, S. \& Mahadevan, S. (1959). Biochem. F. 71, 756.

Goodman, D. S., Blomstrand, R., Werner, B., Huang, H. S. \& Shiratori, T. (1966). f. clin. Invest. 45, 1615 .

Gounelle, H., Marnay, C. \& Blondin, M. (1953). C. R. Séanc. Soc. Biol. 147, 1598.

Greaves, J. D. \& Schmidt, C. L. A. (1937). Proc. Soc. exp. Biol. Med. 37, 40.

Harris, P. L. (1960). Vitams Horm. 18, 34I.

Hashim, S. A. \& Schuttringer, G. R. (1966). Am. F. clin. Nutr. 19, 137.

Hofmann, A. F. \& Borgström, B. (1962). Fedn Proc. Fedn Am. Socs exp. Biol. $21,43$.

Hofmann, A. F. \& Borgström, B. (1964). F. clin. Invest. 43, 247.

Johnson, P. \& Pover, N. F. R. (I962). Life Sci., N.Y. no. 4, p. II 5.

Kayden, H. J., Senior, J. R. \& Mattson, F. H. (I967). F. clin. Invest. 46, 1695.

Kayden, H. J. \& Silber, R. (1965). Trans. Ass. Am. Physns 78, 334.

Kelleher, J., Davies, T. \& Losowsky, M. S. (1969). Biochem. F. 114, 74P.

Klatskin, G. (1954). Ann. N.Y. Acad. Sci. 57, 909.

Klatskin, G. \& Krehl, W. A. (1950). F. clin. Invest. 29, 1528.

Klatskin, G. \& Molander, D. W. (1952). F. clin. Invest. 31, 159.

Klatskin, G. \& Tisdale, W. A. (I957). F. clin. Invest. 36, 1627.

Krishnamurthy, S. \& Bieri, J. G. (1963). F. Lipid Res. 4, 330.

Lloyd, J. K. (1969). Ann. clin. Biochem. 6, 46.

Losowsky, M. S. \& Leonard, P. J. (1967). Gut 8, 539.

Losowsky, M. S., Leonard, P. J., Kelleher, J. \& Pulvertaft, C. N. (1967). Am. Y. clin. Nutr. $20,366$.

Lundh, G. (1962). Gastroenterology 42, 637.

McCormick, E. C., Cornwell, D. G. \& Brown, J. B. (1960). F. Lipid Res. I, 22 I.

Mellors, A. \& Barnes, M. McC. (1966). Br. F. Nutr. 20, 69.

Muller, D. P. R. \& Harries, J. T. (1969). Biochem. F. 112, 28 P.

Pelkonen, R. (1963). Acta med. scand. Suppl. 399, I r.

Pomeranze, J. \& Lucarello, R. J. (1953). F. Lab. clin. Med. 42, 700.

Rose, G. A. (1964). Gut 5, 274.

Rosenkrantz, H., Milhorat, A. T. \& Farber, M. (1953). Metabolism 2, 556.

Schmandke, H. (1967). Wiss. Veröff. dt. Ges. Ernähr. 16, 80.

Schmandke, H. \& Proll, J. (r964). Int. Z. VitaminForsch. 34, 3 I2.

Senior, J. R. (1964). F. Lipid Res, 5, 495.

Simon, E. J., Gross, C. S. \& Milhorat, A. T. (1956). F. biol. Chem. 221, 797. 
Vol. 24

Skinner, W. A., Parkhurst, R. M. \& Alaupovic, P. (1964). F. Chromat. 13, 240.

Society for Analytical Chemistry: Analytical Methods Committee (1959). Analyst, Lond. 84, 356.

Sternberg, J. \& Pascoe-Dawson, E. (1959). Can. med. Ass. F. 80, 266.

Stowe, H. D. (1963). Archs Biochem. Biophys. 103, 42.

Tendille, C., Bats, J., Gervais, C. \& Gaborit, T. (1965). Annls Physiol. veg., Paris. $7,85$.

Thompson, G. R., Lewis, B. \& Booth, C. C. (1966). F. clin. Invest. 45, 94.

van de Kamer, J. H., Huinink, H. T. B. \& Weyers, H. A. (1949). भ. biol. Chem. 177, 347.

Ways, P. O., Parmentier, C. M., Kayden, H. J., Jones, J. W., Saunders, D. R. \& Rubin, C. E. (1967). F. clin. Invest. 46, 35 .

Week, E. F., Sevigne, F. J. \& Ellis, M. E. (1952). F. Nutr. 46, 353.

Wiss, O., Bunnell, R. H. \& Gloor, U. (I964). Vitams Horm. 20, 44I. 